\title{
MONTE CARLO SIMULATION FOR INSURANCE AGENCY CONTINGENT COMMISSION
}

\author{
Mark Grabau \\ Advanced Analytics and Optimization \\ IBM Corporation \\ Westerville, OH 43082, USA
}

\author{
Michael Yurik \\ Analytics Resource Center \\ Westfield Insurance \\ Westfield Center, OH 44251, USA
}

\begin{abstract}
Many insurers pay independent agencies a contingent commission based on the agency's performance. The insurer must accrue funds during the year to recognize the expected contingent commission payout in the financial statements. Westfield Insurance wanted to reduce their accrual forecasting error from 20 percent to less than five percent. We built a Monte Carlo simulation to simulate each Westfield agency's performance. We clustered agencies into representative groups as a proxy for generating correlated random variables and then designed an experiment to shift statistical distributions of agency key performance indicators. The results of the simulation were then used to derive a formula for forecasting expected contingent commissions based on overall company results. The approach, results, and areas for further research are discussed.
\end{abstract}

\section{INTRODUCTION}

Insurers typically sell their products through three different distribution channel types: direct-toconsumer, captive agents, or independent agents. With a direct approach, customers contact the insurer directly, typically by phone or the insurer's website, e.g. GEICO. Captive agents typically have their own brick-and-mortar facility and only sell the products of the insurer they represent, e.g. State Farm. Independent agencies sell competing products from multiple insurers; therefore, the insurer is competing for market share, not just within a geographic area but within its agencies as well. In the independent agency scenario, the insurer incentivizes the agency to sell its products by paying the agency a commission and will often offer an additional commission that is based on actual agency production and profitability.

Westfield Group is headquartered in Westfield Center in northeast Ohio, 44 miles south of Cleveland and 27 miles west of Akron. The company is one of the largest non-public companies in Ohio and has been offering insurance solutions to customers for over 160 years. Six business units offer a variety of insurance products for personal, commercial, and surety customers. Westfield operates in 31 states, with 2012 revenues of approximately $\$ 1.6$ billion. Westfield's insurance products are distributed through a network of approximately 1,000 independent insurance agencies.

Westfield accrues funds throughout the year for the expected contingent commission payout. Historically, Westfield used a lookup table based on corporate key performance indicators (KPIs) to determine a percentage of revenues to record for contingent commissions. However, this approach typically produced an accrual error of over 20 percent. In addition, several days of an analyst's time were required to refresh the lookup table. Westfield's goal was to reduce the accrual forecasting error to less than five percent and reduce the time required for annual maintenance. This paper outlines the approach taken to achieve those goals. 
In order to calculate an agency's contingent commission, data on several KPIs are required for each agency. An agency is excluded from further consideration if certain KPIs do not exceed specified thresholds. If an agency's performance meets or exceeds specified KPI thresholds during a calendar year, the agency will receive a contingent commission payment.

Prior to the approach in this paper, a spreadsheet was used to produce a table lookup using the corporate KPIs, identifying the percentage to be applied to the corporate revenue. The result of that lookup and calculation determined the monthly accrual amount. One major deficiency with the approach was that the table was built assuming the KPIs were normally distributed. Our analysis of the data from 2007 to 2012 using ExpertFit indicated that the normal distribution was not a good representation of those metrics. The Johnson distribution provides a consistently excellent fit across all KPIs over time based on ExpertFit analyses.

\section{THE SIMULATION-ENABLED PROCESS}

The process to produce an equation to predict the contingent commission accrual percentage is depicted in Figure 1.

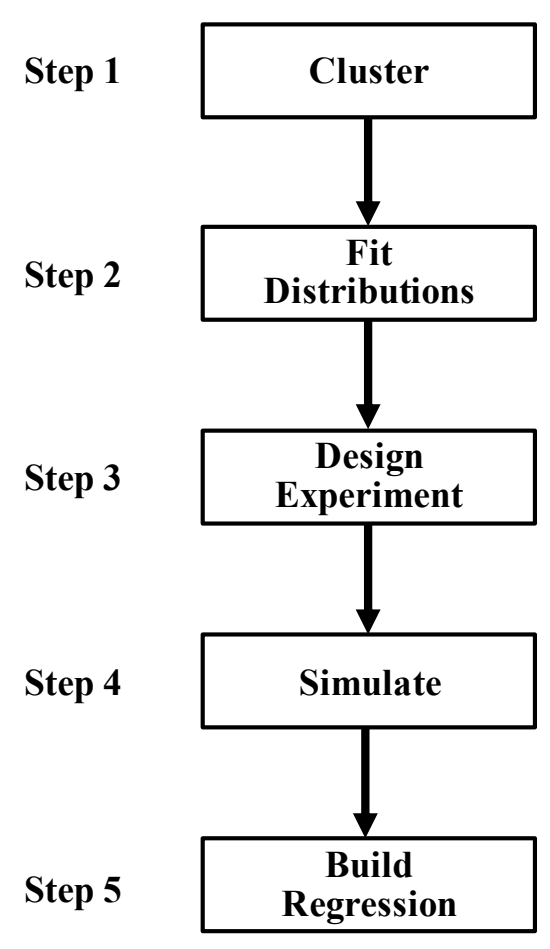

Figure 1: Contingent Commission Forecasting Process

The first step in the process is to group the agencies into clusters using K-means clustering using the agency's KPIs as the variables. IBM SPSS Modeler is used to build the clusters. Table 1 displays the directional results for each of the five clusters that were formed. Ideally, the Monte Carlo simulation in step three would generate correlated random variables for the KPIs; however, this is extremely difficult to achieve as Law (2006) pointed out. As a proxy for generating correlated random variables, distributions are fit to the input variables within each cluster. 
Grabau and Yurik

Table 1: Cluster Characteristics

\begin{tabular}{lccccc} 
& \multicolumn{5}{c}{ Cluster } \\
KPI1 & Low & Average & Average & Low & High \\
KPI2 & Average & Low & High & Average & High \\
KPI3 & Low & High & Average & High & Average
\end{tabular}

The second step in the process is to determine the statistical distribution that best fits the KPIs in each cluster. ExpertFit is used to identify the distribution that best models each variable in each cluster. Distributions are chosen that have a location parameter (Law 2006) that will enable the distribution to be shifted to the left and right according to the experiment in step three.

The third step in the process is to design an experiment to shift the distributions from step two systematically in order to simulate a broad spectrum of agency performance that is accumulated to determine corporate performance. The central composite design, chosen for its orthogonal and rotatable properties as well as the ability to develop a non-linear regression from the outputs, is displayed in Table 2. This is a standard central composite design for this number of factors. Figure 2 depicts how the location of the distribution is shifted according to the experimental design.

Table 2: Central Composite Experimental Design

\begin{tabular}{|c|c|c|}
\hline Run & KPI1 & KPI2 \\
\hline $\mathbf{1}$ & -1 & -1 \\
\hline $\mathbf{2}$ & 1 & -1 \\
\hline $\mathbf{3}$ & -1 & 1 \\
\hline $\mathbf{4}$ & 1 & 1 \\
\hline $\mathbf{5}$ & 0 & 0 \\
\hline $\mathbf{6}$ & 0 & 0 \\
\hline $\mathbf{7}$ & 1.414 & 0 \\
\hline $\mathbf{8}$ & -1.414 & 0 \\
\hline $\mathbf{9}$ & 0 & 1.414 \\
\hline $\mathbf{1 0}$ & 0 & -1.414 \\
\hline $\mathbf{1 1}$ & 0 & 0 \\
\hline $\mathbf{1 2}$ & 0 & 0 \\
\hline
\end{tabular}

The fourth step in the process is to simulate each design point in the experiment and record the corporate outputs from the experiment. Rockwell Automation Arena is used for the simulation modeling. Each agency is run through the simulation once for each replication and 40 replications are conducted at each design point. Each agency's KPIs are modeled with statistical distributions in the simulation. The calculations are made according to section 2 above to determine the agency's contingent commission based on that performance. Each agency's performance is then accumulated to determine overall corporate performance. 


\section{Grabau and Yurik}

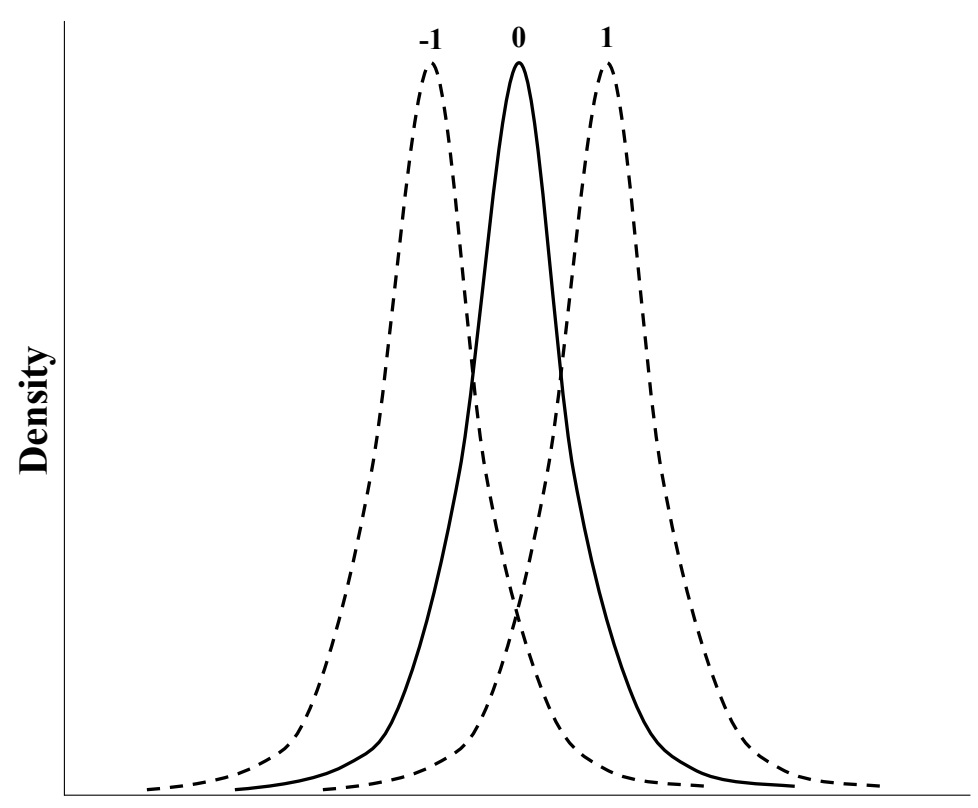

Value

Figure 2: Shifting the Distribution's Location Parameter

The fifth step in the process is to use the KPIs as dependent variables and contingent commission as a percentage of revenue as the dependent variable in a multivariate linear regression. A Cobb-Douglas production function (1) is used as the functional form for the regression for its theoretical advantages as well as its non-linear form.

$$
\frac{\text { Contingent Commission }}{\text { Revenue }}=\beta_{0} K P I 1^{\beta_{1}} K_{P I 2^{\beta_{2}}}
$$

Once the regression equation is built and validated it is then used to determine the accrual multiplier each month.

\section{RESULTS}

The regression from step five consistently produces a high R-squared of 0.9744 . The coefficients are all significant and have the expected signs. The results from using this approach are displayed in Figure 3. The mean absolute percent error over the ten month evaluation period for the original Lookup Table methodology is 24 percent. The mean absolute percent error for the simulation methodology described herein is six percent. The simulation approach delivers a significant improvement in forecasting accuracy over time.

\section{NEXT STEPS}

Given the success of the simulation approach, Westfield is now in its third year of operationalizing the model. The model may be completely refreshed in less than a week, which includes all five steps from Figure 1. In addition, the regression model is used to conduct what-if analyses throughout the year as well as more accurately forecast future years for budgeting purposes. 


\section{Grabau and Yurik}

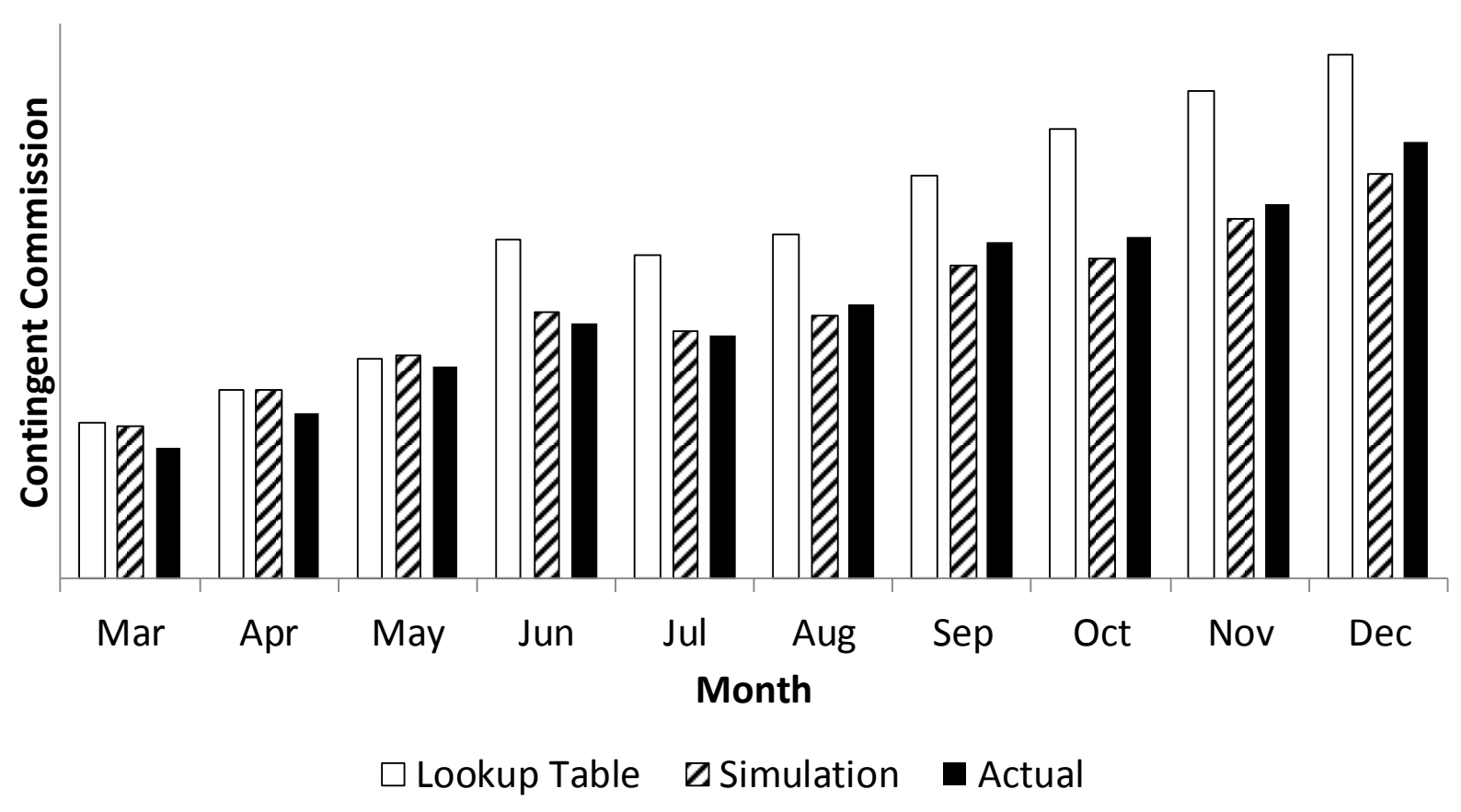

Figure 3: 2012 Forecasting Results

\section{CONCLUSIONS}

We have produced a repeatable process that yields exceptional results. The process results in an equation that can be easily implemented in a spreadsheet and no longer has the deficiency of rounding actual values to align with table lookup values.

With the intractability of generating correlated random variables, we proxy this by mathematically segmenting agencies into similar groups. This produces results such that the forecasting error for the contingent commission accrual has been dramatically reduced. With forecast accuracy near the objective and with the ease of model maintainability, Westfield continues to use this methodology to generate its contingent commission accrual.

\section{REFERENCES}

Law, A. L. 2006. Simulation Modeling and Analysis. 4th ed. New York, New York: McGraw-Hill, Inc.

\section{AUTHOR BIOGRAPHIES}

MARK GRABAU is an Associate Partner in IBM's Business Analytics and Optimization service line. He leads the North America Advanced Analytics and Optimization practice for the Financial Services Sector at IBM and has over 20 years of experience building advance analytics models supporting the marketing and operational functions of large Financial Services, Retail, and Government organizations. Mr. Grabau has managed large, complex analytics projects while providing technical oversight to model design, development, and deployment. He has published 12 refereed papers on the application of advanced analytics to real-world business problems. Mr. Grabau is a Lean Six Sigma Blackbelt and holds M.S. degrees in Operations Research and Statistics from the Colorado School of Mines and a B.S. in Operations Research from the United States Air Force Academy. His email address is mark.grabau@us.ibm.com. 
MICHAEL YURIK is a Business Intelligence Data Analyst in Westfield Insurance's Analytics Resource Center. He is responsible for all independent agency's contingent commission calculations and has worked in various business units at Westfield Insurance for the past 20 years. Prior to joining Westfield Insurance Mr. Yurik was an accountant for the Richard E. Jacobs Group, a national real estate developer. Mr. Yurik holds a M.B.A. degree specializing in Finance from Ashland University and a B.S. in Accounting from the University of Akron. His email address is michaelyurik@westfieldgrp.com. 